\title{
International Comparisons of Some Healthcare Delivery Impacts on Vulnerable Populations
}

\author{
Howard A. Palley ${ }^{1}$
}

Published online: 2 August 2016

(C) Springer International Publishing 2016

\section{Special Issue Introduction}

Nations with national health delivery systems utilize a mix of governmental and private services. This mix differs from nation to nation and is related to institutional development, ideology and culture, governmental organization, as well as funding arrangements (Costa-Font and Greer 2013; Flood and Gross 2014; Nathanson 2007; Riggs 1964). While all national healthcare delivery systems combine in some manner a public/private sector mix, in both predominantly taxfinanced public national healthcare delivery systems and social insurance systems as well as in more predominantly mixed public/private sector-based healthcare delivery systems, equity and universal access is often difficult to achieve for economically marginal, often indigenous groups - due to the impact of social determinants of health - or the fact that individuals inhabit regions that lack an adequate healthcare delivery system (Ho 2014; Flood 2014; Nedwick 2014; Prado 2014). In the forthcoming articles, we are examining the public/private mix in the delivery of healthcare services in its varied nature. As we shall see, this public/private sector mix has the potential to expand the availability of care to low-income groups, but it also has the potential to provide unequal and inequitable patterns of care encompassing those persons with adequate coverage for quality health care and low-income groups with more minimal levels of care.

Howard A. Palley

hpalley@ssw.umaryland.edu

1 Professor Emeritus, School of Social Work, University of Maryland and Distinguished Fellow, Institute for Human Services Policy,

University of Maryland, 525 West Redwood Street,

Baltimore, MD 21201, USA
However, a vigorous public regulatory framework, conscientiously implemented, can result in a public/private sector mix which provides a broad base of quality health services in an equitable manner (Reinhardt 2004; Rosenau 2003; Rosenau and Lako 2008; Palley et al. 2012). Such decisionmaking involves political dispositions to act and ideological policy choices (Di Matteo 2009). However, a danger is the problem of "capture" or undue influence in the policy process and in particular the regulatory process by narrow interest groups (stakeholders) such as those occurred with the influence of the pharmaceutical industry in the drug titles of Medicare and, more recently, the Affordable Care Act in the USA (Cannon 2013, particularly at 147; Pomey et al. 2007). The extent of the influence of the pharmaceutical industry on all levels of government in the USA is explored in Marcia Angell's study, "The truth about the drug companies: how they deceive us and what to do about it" (Angell 2005). Another problem is that private commercial enterprises may seek to avoid the regulatory rules by "gaming" the system so that the regulatory processes do not take hold. This is discussed with regard to nursing homes in a recent study by Laura Katz Olsen (2016). Many of these matters are related to the international contributions to this issue of Global Social Welfare.

Regarding the USA, Camillo discusses the current mixed public/private healthcare delivery system which, in 2014, the federal, state, and local government spent $45 \%$ of US expenditures and the private expenditures were $55 \%$ (Office of Actuary, Centers for Medicare, and Medicaid Services 2015). She notes that the passage of the Patient Protection and Affordable Care Act has provided increased access for many of our poor residents eligible for the federal/state Medicaid program which serves our poorest residents. And it also builds on the mixed nature of the system by providing federally subsidized private insurance policies through a Health Insurance Market Place Program (Health 
Exchanges) - administered by either the state or by the federal government - if the state chooses that option. The program also subsidizes Accountable Care Organizations which have the goal of coordinating care in the mixed system in a manner which would reduce costs, although it is not clear at this point that such organizations will reach that goal (Grogan 2015; Pear 2016). Thirty-three million residents of the USA, $10.4 \%$ of the US population still lack health insurance coverage in our complex public/private healthcare delivery system, although between 2013 and 2014, the number of uninsured dropped by 8.8 million (Smith and Medalia 2015). Also, as Camillo notes, the political compromises necessary for the passage of the Affordable Care Act still leave the US healthcare system as the most expensive national healthcare system - amounting to $17.5 \%$ of the US Gross National Product or US\$3 trillion in 2014 (Office of Actuary, Centers for Medicare, and Medicaid Services 2015) and, as Camillo has observed, with unresolved issue of social equity and cost control (also see Grogan 2015).

Regarding Canada, Marchildon and Allin report mixed findings where about $70 \%$ of expenditures for healthcare delivery are public and $30 \%$ are private. They characterize the Canadian healthcare delivery system as "deep but narrow" offering complete coverage with national standards for medically necessary hospital, diagnostics, and physician services but not establishing national standards for other services such as chronic care services and pharmaceutical coverage. While there are some possible limitations observed for poorer individuals in getting a first visit to a primary care physician for a referral to a specialist, once achieving a primary care visit, in part due to the prevailing fee-for-service arrangements, there is no apparent "pro-rich specialty" inequity in achieving appropriate care in most provinces - except for the provinces of British Columbia and Ontario. Also given the aforementioned lack of national standards, regional equity with regard to pharmaceutical and chronic care services differs between provinces and territories. And the private system has expanded significantly in the area of diagnostic clinic charges that are covered in most cases by the provincial and territorial Medicare systems. Where marketization occurs in the areas of long-term care and access to pharmaceuticals and to dental care, barriers to services for low-income groups may be present.

As Toth notes in reviewing the Italian health system which is primarily public and universal, there is a private component which accounts for $23 \%$ of healthcare expenditures and which is largely out of pocket. This means that individuals with greater disposable income can afford additional services to those provided by the public system and have somewhat greater freedom in choosing a provider. And those in the mezzojourno (Italy's south) have greater freedom to secure health care in northern provinces which are often viewed as providing higher quality care.
Regarding Spain, Pérez Durán has observed the austerity policies demanded by "the Troika," e.g., the European Commission, the European Central Bank, and the International Monetary Fund, have been perceived by the more affluent as a reason for acquiring private health insurance in order to have more choice of physician and hospital services as well as reduced waiting time. Also as an economic budgetary saving, there has been a contracting out of administrative supervision of the delivery of healthcare services in more conservative regions to private intermediaries. There are indications that this has weakened the oversight of the delivery of health care in these regions. The combination of the weakened public accountability in some regions and the marketing of private health insurance has provided some increased benefit to the more affluent citizens that can afford such additional access to healthcare services. This has raised an increased perception that there is a pattern of developing a higher quality of care for higher-income groups.

Similarly, Gusmano finds that in the Chinese system of healthcare delivery while dominated by public institutions, government spending is still less than a third of total health expenditures and marketization enhances both the development of the private sector and the distribution of public sector health services. Paradoxically, while most healthcare facilities in China are public, the reluctance of the government to expand the revenue base sufficiently leads to many health facilities operating like for profit organizations which seek to increase hospital revenues and that this tendency blunts efforts to provide better outpatient primary care. Also, out-of-pocket spending tends to be highest among rural areas which have less public revenues and among internal migrants who are living outside of the provinces in which they are registered.

In his discussion of Japan's healthcare delivery system, Matsuda notes that, in spite of Japan's almost universal insurance coverage, due to the lack of national government standards for delivery of services and the often lack of efficient local coordination of healthcare services, marginal lowincome groups are often underserved. (The physician-led clinics which Matsuda mentions may lead highly-trained specialists to leave hospital-based practices and seek higher incomes in physician-run clinics emphasizing primary care services. This leads to shortages of specialist healthcare services in some regions.) Matsuda concludes that "While it is critical to share objectives among stakeholders to achieve socially desirable results, the current situation in Japan requires the mainstreaming of issues of healthcare access of low-income people...."

In terms of securing accessible and equitable healthcare delivery, in spite of recent improvements, Brazil's healthcare delivery is characterized by an unequal class system. As Lobato, Vaitsman, and Rubeiro note, the scarcity and poor quality of public primary care and public hospital services has led high- and middle-income groups to use the voluntary 
private sector which is covered by private health insurance. While private health insurance has become more available to lower-income consumers, this insurance coverage has been of lower quality and poorly regulated. The authors also note that the private insurance companies seek to transfer high-cost cases to the public healthcare delivery system.

As the contributors to this volume note, all nations utilize a mix of public and private healthcare delivery services. On the positive side, the properly regulated private for-profit and voluntary services - may extend the availability and access of services to meet the healthcare needs of citizens and residents. On the other extreme, lacking proper accountability, the public/private sector mix, can lead to a substantial leakage of revenues that go into areas other than the delivery of healthcare services, such as administration and billing, executive salaries, and excessive corporate profits. In addition, excessive marketization in the healthcare system can result in a lack of social equity based on income level and the market power of the more affluent.

\section{References}

Angell, M. (2005). The truth about the drug companies: how they deceive us and what to do about it. New York, NY: Random House Trade Paperbacks.

Cannon, J. (2013). The legislative history of the Affordable Care Act: how legislative procedure shapes legislative history. Law Library Journal, 105(2), 131-173.

Costa-Font, J., \& Greer, S. L. (2013). Federalism and decentralization in European health and social care. Basingstoke: Palgrave Macmillan.

Di Matteo, L. (2009). Policy choice or economic fundamentals: what drives the public-private health expenditure balance in Canada. Health Economics, Policy and Law, 4, 29-53.

Flood, C. M. (2014). Litigating health rights in Canada: a white knight for equity? In C. M. Flood \& A. Gross (Eds.), The right to health in the public/private divide: a global comparative study (pp. 79-106). New York: Cambridge University Press.

Flood, C. M., \& Gross, A. (Eds.) (2014). The right to health in the public/ private divide: a global comparative study. New York: Cambridge University Press.

Grogan, C. M. (2015). The role of the private sphere in U.S. healthcare entitlements: increased spending, weakened public mobilization and reduced equity. The Forum, 13(1), 119-142.
Ho, C. S. (2014). Health rights at the juncture between state and market: the People's Republic of China. In C. M. Flood \& A. Gross (Eds.), The right to health care in the public/private divide: a global comparative study (pp. 263-287). New York: Cambridge University Press.

Nathanson, C. A. (2007). Disease prevention as social change: the state, society and public health in the United States, France, Great Britain and Canada. New York, NY: Russell Sage Foundation.

Nedwick, C. (2014). Promoting access and equity in health: assessing the National Health Service in England. In C. M. Flood \& A. Gross (Eds.), The right to health in the public/private divide: a global comparative study (pp. 107-130). New York: Cambridge University Press.

Office of Actuary, Centers for Medicare and Medicaid Services. (2015). 2014 National health expenditures. Accessed at http://cms. gov/Research-Statistics-Data-and-Systems/Statistics-Trends-andReports/NationalHealthExpendData/NationalHealth AccountsHistorical.html.

Olson, L. K. (2016). Elder care journey: a view from the front lines. New York: State University of New York Press.

Palley, H. A., Pomey, M.-P., \& Adams, O. B. (2012). The political and economic sustainability of health care in Canada: private-sector involvement in the federal provincial health care system. Amherst, NY: Cambria Press.

Pear, R. (2016). I.R.S. ruling is potential obstacle to health networks promoted by Obama. New York Times, May 30, A8.

Pomey, M.-P., Forest, P.-G., Palley, H. A., \& Martin, E. (2007). Public/ private partnerships for prescription drug coverage: outcomes in Quebec's universal health insurance program, in comparison to the Medicare Prescription Drug Program in the United States. The Milbank Quarterly, 85(3), 469-498.

Prado, M. M. (2014). Provision of health care services and the right to health care in Brazil: the long, winding, and uncertain road to equality. In C. M. Flood \& A. Gross (Eds.), The right to health in the public/private divide: a global comparative study (pp. 309-344). New York: Cambridge University Press.

Reinhardt, U. (2004). The Swiss health system: regulated competition without managed care. Journal of the American Medical Association, 292(10), 1227-1231.

Riggs, F. W. (1964). Administration in developing countries: the theory of prismatic federalism. Boston: Houghton Mifflin.

Rosenau, P. V. (2003). The competition paradigm: America's romance with conflict, contest and commerce. Lanham: Roman and Littlefield Publishers.

Rosenau, P. V., \& Lako, C. A. (2008). An experiment with regulated competition and individual mandates for universal health care: the new Dutch health insurance system. Journal of Health Politics, Policy and Law, (1), 1031-1055.

Smith, J. C., \& Medalia, C. (2015). Health insurance coverage in the United States, 2014. U.S. Census Bureau, current population reports. Washington, DC: U.S. Government Printing Office. 